SISTEMA
ELETRÔNICO
DE REVISTAS
SER I UFPR

\title{
Programa Dinheiro Direto na Escola - escolas sustentáveis, em um município do Estado da Bahia: contribuições, desafios e perspectivas
}

\section{Direct Money in School Program - sustainable schools, in a municipality of the state of Bahia: contributions, challenges and expectations}

\author{
Adriana Oliveira de SOUZA SILVA ${ }^{1,2, *}$, Sandra Lúcia da Cunha e SILVA², Débora Cardoso da SILVA ${ }^{2}$, Marco \\ Antonio Leandro BARZANO ${ }^{3}$, Sillas Oliveira SANTOS ${ }^{4}$ \\ ${ }^{1}$ Instituto Federal de Educação, Ciência e Tecnologia Baiano (IF Baiano), Itapetinga, BA, Brasil \\ ${ }^{2}$ Programa de Pós-Graduação em Ciências Ambientais (PPGCA), Universidade Estadual do Sudoeste da Bahia (UESB), Itapetinga, BA, Brasil. \\ ${ }^{3}$ Programa de Pós-Graduação em Educação Universidade Estadual de Feira de Santana (UEFS), Feira de Santana, BA, Brasil. \\ ${ }^{4}$ Universidade Estadual do Sudoeste da Bahia (UESB), Itapetinga, BA, Brasil. \\ *E-mail de contato: drikaoss1977@gmail.com
}

Artigo recebido em 11 de abril de 2019, versão final aceita em 14 de outubro de 2019.

RESUMO: $\quad$ O Programa Dinheiro Direto na Escola - Escolas Sustentáveis é um programa do governo federal vinculado ao Fundo Nacional de Desenvolvimento da Educação que disponibiliza auxílio financeiro a fim de fomentar a sustentabilidade socioambiental nas escolas da educação básica a partir de três dimensões inter-relacionadas: gestão, currículo e espaço. Esse artigo avaliou a implementação do Programa Dinheiro Direto na Escola Escolas Sustentáveis em 41 escolas da rede municipal de ensino de um município do Estado da Bahia, pontuando as contribuições no que concerne ao espaço físico, à gestão e à inserção curricular da temática ambiental, bem como aos desafios e às perspectivas para a concretização da escola como espaço educador sustentável, de acordo com os objetivos do Programa Nacional Escolas Sustentáveis. Adotando uma abordagem qualitativa e descritiva, com apoio da análise quantitativa, foram utilizados como instrumentos metodológicos a análise documental, entrevista e observação in loco. Foram entrevistados a servidora responsável por acompanhar a execução dos recursos financeiros liberados; o assessor pedagógico da Secretaria Municipal de Educação e os gestores e coordenadores pedagógicos de cada escola. A análise documental se deu a partir da avaliação do Plano de Ação, da Ata, da Prestação de Contas e do Projeto Político Pedagógico. Também foi realizada a observação in loco, com o objetivo de confrontar os dados obtidos por meio da entrevista e da análise documental com a realidade local. A análise demonstrou que o maior obstáculo para a efetividade desse 
Programa foi a falta de capacitação, sendo a preparação dos profissionais imprescindível para uma melhor aplicabilidade dos recursos, assim como para um maior envolvimento no programa. Além disso, foi detectada falta de articulação entre os eixos Gestão, Currículo e Espaço Físico, aspecto importante para se consolidar a sustentabilidade socioambiental no ambiente escolar conforme os princípios do Programa Nacional Escolas Sustentáveis.

Palavras-chave: educação ambiental; ciências ambientais; pedagogia.

ABSTRACT: Direct Money in School Program - Sustainable Schools is a federal government program linked to the National Fund for Education Development, which provides financial support in order to foster socio-environmental sustainability in primary schools from three interrelated dimensions: management, curriculum and space. This paper aimed to evaluate the implementation of the Direct Money in School Program - Sustainable Schools in 41 public schools in a municipality of the State of Bahia, highlighting the contributions concerning to physical space, management and curricular implementation of the environmental matter, as well as the challenges and perspectives for the realization of the school as a sustainable educator space, according to the National Sustainable Schools Program. Adopting a qualitative and descriptive approach, with the support of the quantitative analysis, it were used as methodological instruments documentary analysis, interview and in loco observation. It were interviewed the servant responsible for monitoring the execution of the financial resources released, the pedagogical advisor of the Municipal Education Department and the pedagogical managers and coordinators of each schooland coordinators of each school. The documentary analysis was based on the evaluation of the Action Plan, the Minutes, the Accountability and the Political Pedagogical Project. It was also carried out the in loco observation, with the objective to compare the data obtained through the interview and the documentary analysis with the local reality. According to analysis, the greatest obstacle to the effectiveness of this Program was the lack of capacity building, and this preparation of professionals is essential for a better applicability of resources, as well as greater involvement in the program. Furthermore, there was a lack of articulation between the Management, Curriculum and Physical Space strands, an important aspect to consolidate social and environmental sustainability in the school environment according to the principles of the National Sustainable Schools Program.

Keywords: environmental education; environmental sciences; pedagogy.

\section{Introdução}

AAgenda 2030, documento resultante da Reunião da Cúpula da Organização das Nações Unidas (ONU), em setembro de 2015, ao descrever "Nosso mundo hoje", afirma que "o esgotamento dos recursos naturais e os impactos negativos da degradação ambiental" colocam em risco a "sobrevivência de muitas sociedades, bem como dos sistemas biológicos do planeta" (ONU, 2015, p. 6).

Essa situação que a humanidade vivencia atualmente, também conhecida como crise socioambien- tal, é, em grande parte, resultado de um modelo de desenvolvimento econômico que se acentuou com a Revolução Industrial, cujo êxodo rural desencadeou um crescimento urbano desordenado, bem como o agravamento das condições de saneamento básico e dos problemas de saúde. Assim, a população já sentia, numa menor intensidade talvez, a íntima relação entre os aspectos sociais e ambientais.

$\mathrm{Na}$ visão de que os recursos naturais eram infinitos, o capitalismo crescia e a crise ambiental ainda permanecia invisível para muitos. Apenas em meados de 1960, com o amadurecimento do "movimento 
ecologista", é que a humanidade começou a ter uma percepção diferente.

Na tentativa de mitigar ou reduzir os impactos negativos originados de 200 anos de degradação "in-consciente", a educação foi idealizada como importante aliada para a consecução de um mundo mais sustentável.

Inicia-se, então, estudos para o desenvolvimento de políticas públicas nesta área, a fim de incluir a educação ambiental no processo educativo e de articular elementos necessários à obtenção da sustentabilidade ambiental dentro e fora do ambiente escolar.

Trilhando por esse caminho, foi sancionada no Brasil, em 1999, a Lei n. ${ }^{\circ}$ 9.795, instituindo a Política Nacional de Educação Ambiental e, nesse contexto, as discussões foram aperfeiçoadas e, em 2008, o Ministério do Meio Ambiente (MMA) elabora o Plano Nacional sobre Mudança do Clima advertindo para necessidade de criação de espaços educadores sustentáveis para enfrentamento das mudanças climáticas. Com base nessa recomendação o Ministério da Educação (MEC) propôs “a implementação de programas de espaços educadores sustentáveis com readequação de prédios (escolares e universitários) e da gestão, além da formação de professores e inserção da temática nos currículos e materiais didáticos" (MMA, 2008, p.113).

Após muitos estudos da Coordenadoria Geral de Educação do MEC, de membros dos Ministérios do Meio Ambiente, da Ciência, Tecnologia e Inovação e da Integração Nacional, assim como de três universidades federais (Mato Grosso (UFMT), Mato Grosso do Sul (UFMS) e Ouro Preto (UFOP)), foi lançado em 2010 o Programa Nacional Escolas Sustentáveis - PNES, tendo como primeira ação a realização do processo formativo em educação ambiental denominado "Escolas Sustentáveis e Com-Vida", vinculado à Universidade Aberta do Brasil (UAB).

Entretanto, a implementação do Programa Nacional Escolas Sustentáveis - PNES nas escolas, apenas foi possível em 2013, por intermédio do Programa Dinheiro Direto na Escola - Escolas Sustentáveis (PDDE-ES) que, de acordo com a Resolução CD/ FNDE n. ${ }^{\circ} 18$, de 21 de maio de 2013, tem como base o investimento de recursos financeiros, de caráter suplementar, disponibilizados pelo Fundo Nacional de Desenvolvimento da Educação (FNDE), visando incentivar o estabelecimento da educação ambiental e a sua implantação em escolas da educação básica das redes distrital, estadual ou municipal (Brasil, 2013, p. 1). Com isso, a proposta Escolas Sustentáveis se materializou como uma ação de política pública para a educação ambiental no Brasil, visando transformar as escolas de educação básica em espaços educadores sustentáveis.

As Políticas Públicas possuem a capacidade de oportunizar a melhoria da qualidade de vida da população através da implementação de medidas que garantam o bem-estar comum. Conforme ressaltado por Souza (2006), as políticas públicas devem envolver uma série de processos após sua decisão e proposição, como implementação, execução e avaliação.

No entanto, Bastos \& Rabinovici (2016) advertem que não existem informações sobre o resultado do projeto das escolas contempladas no Programa Dinheiro Direto na Escola - Escolas Sustentáveis e, diante disso, a avaliação do Programa Nacional Escolas Sustentáveis ficou prejudicada.

Bonamino \& Sousa (2012) destacam que "a avaliação de políticas e programas públicos ganha, assim, um lugar de destaque como meio para mensurar seu desempenho e exercer a prestação de contas à sociedade". Nesse sentido, essa investigação opor- 
tuniza à comunidade científica e aos nossos gestores um recorte do PNES como política pública para a educação ambiental no Brasil, colaborando para o debate sobre a eficiência dos programas nessa área.

Diante disso, este artigo avaliou a implementação do Programa Dinheiro Direto na Escola - Escolas Sustentáveis, nas escolas da rede municipal de ensino, de um município do Estado da Bahia, pontuando as contribuições no que concerne ao espaço físico, à gestão e à inserção curricular da temática ambiental, bem como aos desafios e às perspectivas para a concretização da escola como espaço educador sustentável, de acordo com os objetivos do Programa Nacional Escolas Sustentáveis.

\section{Metodologia}

O estudo foi desenvolvido em um município do Estado da Bahia, no período de 2017 a 2018. O projeto foi submetido ao Comitê de Ética em pesquisa CEP/UESB e somente foi iniciado após sua aprovação (parecer n. ${ }^{\circ}$ 2.521.296).

A pesquisa configura-se como um estudo de caso que, conforme Fonseca (2002), é um estudo de uma entidade bem definida, com o intuito de conhecer em profundidade uma determinada situação procurando descobrir o que há nela de mais essencial e característico. Nesse tipo de estudo, o pesquisador não intervém sobre o objeto, revelando-o tal como ele o percebe.

Ante exposto, adotou-se a abordagem qualitativa e descritiva, com apoio da análise quantitativa, pois, as "abordagens qualitativas, que tendem a serem associadas a estudos de caso, dependem de estudos quantitativos, que visem gerar resultados generalizáveis" (Günther, 2002, p. 204).
Ainda segundo Günther (2002) "a pesquisa qualitativa considera cada problema objeto de uma pesquisa específica para a qual são necessários instrumentos e procedimentos específicos, assim foram utilizados como instrumentos metodológicos a análise documental, a entrevista e a observação in loco.

Inicialmente foi feito o levantamento das escolas municipais que foram contempladas no Programa Dinheiro Direto na Escola- Escolas Sustentáveis (PDDE-ES), nos anos de 2013 e 2014. As escolas, alvos da pesquisa, foram identificadas pelo codinome composto pela sigla UE (Unidade Escolar), seguido de um número definido pelos pesquisadores, tal como UE35, mantendo assim o anonimato das escolas, bem como do município.

Posteriormente, foram realizadas entrevistas com a servidora lotada na Secretaria Municipal de Educação - SME, responsável por acompanhar a execução dos recursos liberados pelo Fundo Nacional de Desenvolvimento da Educação (FNDE) e o assessor pedagógico da SME. Também foram entrevistados os gestores e coordenadores pedagógicos das escolas participantes do estudo, totalizando 45 entrevistados. A escolha dos participantes foi proposital e levou em consideração "suas características e/ou funções", "disponibilidade dos sujeitos" e, principalmente seu "amplo conhecimento do contexto estudado" (Alves-Mazzotti \& Gewandsznajder, 2002).

As entrevistas foram realizadas individualmente, conduzidas a partir de um roteiro estruturado construído em três partes: a primeira sobre identificação e perfil, a segunda referente aos conhecimentos sobre políticas públicas para educação ambiental e a terceira parte envolveu questões sobre o PNES, totalizando 25 perguntas abertas. Foram 
abordados aspectos como concepção de educação ambiental, além de percepção e conhecimento desses sujeitos sobre políticas públicas para educação ambiental. Refinando a pesquisa, examinou-se a compreensão dos entrevistados sobre o Programa Nacional Escolas Sustentáveis e sobre o Programa Dinheiro Direto na Escola - Escolas Sustentáveis; ações desenvolvidas, abrangência e a forma como foi implementado o Programa; contribuições do PDDE-ES para mudanças no espaço físico da escola, na gestão e no currículo; desafios e dificuldades enfrentados para transformar a escola num espaço educador sustentável; e, se houve mudanças de valores, atitudes e comportamentos.

Anterior à realização das entrevistas, cada entrevistado foi informado sobre os objetivos da pesquisa e sobre as questões que seriam abordadas. Foi informado também que a mesma seria gravada e que os entrevistados não seriam identificados, assim como a escola e o município, sendo garantida a liberdade de não participar da pesquisa e que caso decidisse por participar, a autorização do uso da sua entrevista seria formalizada através da sua assinatura no Termo de Consentimento Livre e Esclarecido - TCLE. Cientes dos procedimentos, após leitura da transcrição do seu depoimento todos os entrevistados assinaram o TCLE.

A análise de entrevistas é tarefa bastante complicada e exige muito cuidado com a interpretação (Duarte, 2004, p. 216), assim, optou-se como estratégia a construção do quadro comparativo das contribuições e desafios, atentando para a frequência em que determinadas palavras apareciam, a exemplo de capacitação, recurso, dentre outras palavras.

Paralelamente, foi feita a análise documental em todas as escolas municipais contempladas com o Programa Dinheiro Direto na Escola - Escolas
Sustentáveis (PDDE-ES), nos anos de 2013 e 2014. Nesse procedimento, foram avaliados os documentos resultantes da adesão ao PDDE-ES: o Plano de Ação (lançamento de uma ou mais ações definidas pela comunidade escolar na plataforma do PDDE-ES); as Atas (transcrição das reuniões com a comunidade escolar para planejamento ou reprogramação das ações) e a Prestação de Contas (documentos informando os materiais e bens adquiridos, os serviços contratados e o saldo referente aos recursos recebidos). Além dos documentos resultantes da adesão ao PDDE-ES, também foi analisado o Projeto Político Pedagógico - PPP, a fim de verificar se a educação ambiental é contemplada nesse importante instrumento pedagógico e como essa temática é desenvolvida por cada escola.

Também foi realizada a observação estruturada não-participante. André (2013) destaca a necessidade de se fazer um registro claro e detalhado dos eventos observados para subsidiar futuras análises, assim, foram utilizadas fichas pré-definidas nas quais foram registradas a existência ou ausência de elementos indicadores de práticas pedagógicas e/ou administrativas voltadas para as questões socioambientais, tais como: acessibilidade, uso eficiente da energia elétrica e da água, bem como a existência de espaços físicos ao ar livre, como hortas e jardins, visando o estímulo da aprendizagem através da interação do indivíduo com o meio ambiente natural.

As informações, obtidas por meio das observações da realidade local, foram confrontadas com os dados provenientes da entrevista e da análise documental. Essa observação foi realizada em dois momentos: o primeiro, no dia da entrevista, quando foi feita uma visita guiada por todos os ambientes da escola sob a companhia do(a) diretor(a). Geralmente, durante o percurso da observação, os(as) 
diretores(as) costumavam frisar o que foi feito na gestão anterior e em sua gestão e falavam dos planos para o restante do recurso, quando pertinente. Vale ressaltar que o entorno da escola também foi observado a fim de verificar a relação comunidade/escola.

Após análise preliminar dos dados coletados na primeira fase da observação in loco, análise dos documentos e entrevistas, ocorreu o segundo momento da observação, etapa essencial para complementar as informações, visto que possibilitou um olhar mais apurado da realidade de cada unidade escolar.

Tendo em vista, o universo pesquisado e os instrumentos escolhidos, a coleta de dados foi realizada no período de abril a agosto de 2018 e constituiu-se grande desafio. Foi, portanto, realizada a análise dos dados coletados, em acordo com a pesquisa qualitativa e descritiva, com apoio da análise quantitativa, enfatizando as contribuições nos eixos gestão, currículo e espaço físico em cada unidade escolar a partir das orientações do Manual Escolas Sustentáveis, do ano de 2013, e do Guia de Orientações Operacionais, de 2014.

\section{Resultados e discussão}

A abordagem qualitativa possui características básicas, assim, segundo Ferreira (2015) "a análise dos dados computados é feita de forma indutiva e, ao longo dela, dá-se a construção paulatina do quadro teórico". Dessa, maneira, para melhor descrever o fato social em estudo, este tópico (Resultados e Discussão) foi subdividido em oito pontos a seguir:

\subsection{Prévia}

No município pesquisado, foram contempladas com o auxílio financeiro do Fundo Nacional de
Desenvolvimento da Educação (FNDE), através do Programa Dinheiro Direto na Escola - Escolas sustentáveis (PDDE-ES), 42(quarenta e duas) das escolas municipais e, desse total, foram avaliadas 41 escolas, representando $97,6 \%$.

Ao todo, a rede municipal recebeu $\mathrm{R} \$$ 378.000,00 (trezentos setenta e oito mil reais) do Programa Dinheiro Direto na Escola, para a ação agregada Escolas Sustentáveis. Conforme o Manual Escolas Sustentáveis, a distribuição da verba entre as escolas municipais se deu de acordo com o número de alunos matriculados em cada escola, segundo o Censo Escolar do exercício imediatamente anterior. Diante disso, o município recebeu R\$ 22 mil para as duas escolas participantes conforme Censo Escolar de 2012 e R\$356 mil para as escolas que participaram da edição do PDDE-ES ocorrida em 2014, conforme Censo de 2013.

\subsection{Percepção ambiental}

Apoiado no princípio libertário, o Programa Nacional Escolas Sustentáveis - PNES estimula à reflexão, à pesquisa, à descoberta, à autonomia, à participação de toda a comunidade rumo à sustentabilidade. Trajber \& Sato (2010) ressaltam que o objetivo principal do PNES é promover a transformação das escolas em "incubadoras de mudanças", para que possam encontrar possíveis soluções para as dificuldades detectadas.

Para efetivação desse princípio básico, bem como para que a educação para sustentabilidade alcance seus objetivos e seja uma experiência exitosa, é necessário o empenho dos sujeitos envolvidos. Esse empenho está diretamente relacionado ao conhecimento, à percepção das coisas, pois é através 
da percepção que os sujeitos (no caso dessa pesquisa os educadores) irão adquirir, interpretar, organizar e selecionar as informações e, por fim usá-las em seu benefício (ou não).

Diante disso, após conhecer o perfil profissional dos entrevistados, foi dada sequência à entrevista com duas perguntas-chave "Para você o que é educação ambiental?" e "Qual sua visão sobre a Lei Nacional n. ${ }^{\circ}$ 9.795/99, a Lei Estadual n ${ }^{\circ}$ 12.056/2011 e as DCNEA?". Referente ao primeiro questionamento, $88,0 \%$ das respostas expressaram uma relação dicotômica entre ser humano e natureza. Questões sociais, políticas e econômicas não foram incorporados às falas desses sujeitos, indicando uma concepção superficial sobre educação ambiental com predominância dos termos cuidar, conservar e preservar os recursos naturais:

Educação Ambiental é tudo que desenvolve a consciência no aluno a respeito da preservação do meio ambiente, da conservação do meio onde ele vive, do lidar com a questão da água, a produção do lixo, bem como descarte e separação do mesmo, de fazer uso responsável dos recursos. (Diretora UE17)

O discurso dos entrevistados apresentou associação com a concepção naturalista, demonstrando que os sujeitos compreendiam o termo "meio ambiente" como sinônimo de "natureza", além disso, o ser humano foi concebido como principal responsável pelosimpactos negativos ao meio ambiente, conforme depoimento da Diretora UE5:

Os seres humanos sempre acharam que os recursos naturais eram inesgotáveis, que para sempre teríamos água limpa, para sempre teríamos florestas, para sempre teríamos os biomas, os animais, tudo em equilibrio. E o homem começou a fazer uso disso, sem se preocupar com a questão da sustentabilidade e hoje, a nossa geração é a que mais tem sofrido as consequências dessa falta de educação ambiental, a exemplo das alterações do clima e da falta de água, que já é uma realidade em alguns lugares do mundo. (Diretora UE5)

\subsection{Conhecimentos dos documentos legais sobre educação ambiental}

Quando questionados sobre “Qual sua visão sobre a Lei Nacional n. ${ }^{\circ}$ 9.795/99, a Lei Estadual n ${ }^{\circ}$ 12.056/2011 e as DCNEA que instituem a política para educação ambiental para o sistema de ensino na Educação Básica, apenas 29,6\% dos entrevistados revelaram ter conhecimento sobre as legislações e as diretrizes (Tabela 1).

TABELA 1 - Porcentagem dos entrevistados que demonstraram conhecimento sobre os documentos legais que instituem a política para Educação Ambiental para o sistema de ensino na Educação Básica, no Brasil.

\begin{tabular}{lc}
\hline \multicolumn{1}{c}{ CATEGORIAS } & TOTAL $=\mathbf{4 5}$ \\
\hline $\begin{array}{l}\text { Demonstraram algum } \\
\text { conhecimento sobre esses } \\
\text { documentos }\end{array}$ & $29,6 \%$ \\
\hline Respostas sem congruência & $22,2 \%$ \\
\hline $\begin{array}{l}\text { Declararam não conhecer o } \\
\text { teor desses documentos }\end{array}$ & $14,8 \%$ \\
\hline $\begin{array}{l}\text { Não responderam a esta } \\
\text { pergunta }\end{array}$ & $33,4 \%$ \\
\hline
\end{tabular}

FONTE: Próprios autores.

Sobre a Lei Nacional n. ${ }^{\circ}$ 9.795/99, a Lei Estadual $n^{\circ} 12.056 / 2011$ e as DCNEA, os entrevistados frisaram a necessidade de colocar as leis em prática e sugeriram que os setores promotores de desen- 
volvimento educacional proporcionassem o estudo desses documentos entre os educadores:

Tem que ser mais trabalhado com o professor, porque ouvimos falar, mas não aprofundamos nessas leis e também não colocamos em prática, talvez por falta de conhecimento. (Diretora UE29)

Se formos analisar, a nivel de Brasil, constataremos uma evolução no que diz respeito à legislação, diversas políticas já foram implantadas e são discutidas, ainda que timidamente. Sinto falta de uma atuação maior por parte do MEC para que efetivamente a Educação Ambiental seja uma realidade em nossas escolas. (Assessor Pedagógico da SME)

\subsection{Conhecimento sobre o PNES}

Foi solicitado aos entrevistados que falassem um pouco sobre as perspectivas ao tomar conhecimento de que a "sua" escola havia sido contemplada no PDDE - ES:

A perspectiva era de que trouxesse algum beneficio para a escola. (Diretora UE27)

Quando veio essa proposta que envolvia recursos, nós pensamos logo nas conquistas e aquisições para melhoria do trabalho pedagógico. (Diretora UE20)

Observou-se nos relatos que a palavra "perspectiva" denota "expectativa" ou "esperança". Em relação à perspectiva sobre o PDDE-ES, 57,0\% dos entrevistados apresentaram uma visão que remete à ideia de auxílio financeiro para atender às necessidades da escola, visando proporcionar "condições favoráveis à melhoria da qualidade de ensino". $\mathrm{O}$ artigo $3^{\circ}$ da Resolução CD/FNDE n. ${ }^{\circ} 18 / 2014$ estabelece que os recursos oriundos do PDDE-ES “devem ser empregados na implementação de ações que propiciem condições favoráveis à melhoria da qualidade de ensino" como destacam as diretoras das UE's 20 e 27, contudo, vale destacar que por se tratar de uma ação agregada específica, essa "melhoria" visa precisamente à promoção da sustentabilidade socioambiental nas unidades escolares. :

Constatou-se que 43,0\% dos entrevistados esboçou sua visão sobre a proposta Escola Sustentáveis a partir de uma visão ecológica da educação ambiental, sendo a perspectiva socioambiental inserida timidamente no discurso e na prática pedagógica:

\begin{abstract}
Quando penso em "escolas sustentáveis" imagino que é trabalharmos para tornar o ambiente escolar mais prazeroso, mais adequado para o desenvolvimento do processo de ensino-aprendizagem, destacando a importância da sustentabilidade, discutindo com os alunos sobre as questões ambientais, ensinar que há maneiras de utilizar os recursos naturais sem prejudicar o meio ambiente. (Diretora UE13)
\end{abstract}

A intenção com essas perguntas era conhecer a relação entre saber-poder dos entrevistados, pois como afirma Silva (2005) o currículo é "uma questão de saber, poder e identidade" e, assim sendo, quem está no poder vai levar a política que acredita, e, nesse caso, os gestores e/ou coordenadores vão empenhar forças e energia no currículo ou no(s) tema(s) que eles conhecem e acreditam. Assim, as políticas para educação ambiental podem transcender da teoria para a prática a depender do pensamento dos educadores (professores, gestores, coordenadores, etc.), pois quando esses sujeitos se identificam com a questão ambiental, conseguem despertar no restante da comunidade escolar o interesse por essa temática. 
Constatou-se que muitas escolas do município analisado aderiram ao PNES, porém, 14,3\% dos (as) gestores (as) tomaram conhecimento do recebimento do recurso a partir de nossa visita, quando lhes foi apresentado a planilha elaborada pelos pesquisadores, a partir de dados coletados no sítio do FNDE, na aba "liberações". Diante dessa situação, a entrevista foi agendada para outro momento a fim de que o/a(s) gestores (as) buscassem informações na pasta de documentos do PDDE-ES que cada escola costumava colecionar ou na plataforma do PDE Interativo ou junto a Secretaria de Educação.

Geralmente, quando do retorno a campo para continuidade da coleta, os(as) diretores(as) apresentavam o extrato com saldo residual do PDDE-ES e pediam opinião de como executar aquele valor, e a orientação era acessar o Plano de Ação e as atas de reunião com a Unidades Executoras (UEx), pois esses documentos detalhavam onde deveriam ser aplicados os recursos. Caso todas as ações planejadas tivessem sido realizadas, a comunidade e a UEx deveriam fazer um novo diagnóstico para detectar novas necessidades socioambientais da escola. Quanto a isso, o assessor pedagógico da Secretaria Municipal de Educação esclareceu como se deu a participação da atual gestão desse órgão na aplicação do recurso:

Por parte da Secretaria Municipal de Educação sempre há orientação para que o recurso seja aplicado de forma correta, não havendo diretamente uma intervenção. Segundo levantamento, foi detectado que esses recursos entraram nas contas da escola nos anos de 2013, 2014 e 2015, como assumimos em 2017, então não tivemos oportunidade de opinar, ou seja, direcionar. (Assessor Pedagógico SME)
A maioria dos (as) gestores (as) e coordenadores (as) entrevistados (as) não soube informar como a escola conheceu o Programa Nacional Escolas Sustentáveis e como se deu a adesão de sua escola ao PDDE-ES, justificando que "não fazia parte da equipe gestora e não ficou sabendo dos detalhes". Para melhor entender a justificativa, faz-se necessário trazer as seguintes informações:

- $\quad 80,5 \%$ das escolas contempladas com o PDDE-ES receberam a segunda parcela do recurso em 2016, e muitas delas não conseguiram executar o recurso nesse exercício, logo tiveram que reprogramar o saldo para o exercício seguinte como estabelece a Resolução CD/FNDE n. ${ }^{\circ}$ 18/2014;

- $\quad$ Em 2017, houve posse do novo gestor do poder executivo municipal e, como de costume, alterações em toda equipe diretiva, inclusive nas escolas da rede municipal de ensino;

- Não é praxe, nas escolas do município pesquisado, acontecer uma fase de transição, momento em que os gestores atuais passam para seus sucessores informações sobre orçamento financeiro e recursos disponíveis, ações realizadas e a realizar.

Diante dessas informações, vale destacar o quanto é delicada a situação da política de governo, visto que, a cada quatro ou oito anos, deve-se "recomeçar do zero" ou dar, a esmo, continuidade a ações importantes. Ressalta-se ainda que, apesar de ser uma atitude comum em vários municípios do Brasil, tal prática em nada pactua com os princípios da Educação, sendo urgente uma política de Estado.

Considerando a declaração dos entrevistados de que "não fazia parte da equipe gestora e não ficou 
sabendo dos detalhes" do PNES, percebe-se que, no município pesquisado, a gestão escolar baseia-se num processo disperso, segmentado e atrelado a posições político-partidárias, levando o PNES a se configurar mais como uma política de governo que de Estado. Diante desse contexto, constatou-se que apenas os(as) educadores(as) que exerciam alguma função na equipe gestora anterior souberam informar sobre a adesão ao PDDE-ES, computando $26,2 \%$ dos entrevistados que ajudaram a elucidar o questionamento:

Eu estava como gestora em outra escola e me lembro que conhecemos o Programa através da Secretaria de Educação. (Coordenadora Pedagógica da UE15)

Eu estava atuando como coordenadora pedagógica em outra escola, mas me lembro bem que foi via Secretaria Municipal de Educação. (Diretora da UE20)

A Resolução CD/FNDE n. ${ }^{\circ}$ 18/2013, que trata sobre a destinação dos recursos financeiros para o PNES, estabelece em seu artigo $4^{\circ}$ os requisitos para participarem do Programa:

I - situar-se em município sujeito a emergências ambientais, (...); II - ter participado da III Conferência Nacional Infanto-Juvenil pelo Meio Ambiente (CNIJMA) e/ou constar do cadastro das escolas que realizaram a Conferência na Escola, da IV CNIJMA (...); e III - ter participado do Processo Formativo em Educação Ambiental: Escolas Sustentáveis e Com-Vida. (FNDE, 2013)

Complementando essa informação, o Manual Escolas Sustentáveis apresenta um barema para classificação, no qual o primeiro critério tem peso
4 e os demais critérios peso 3, para cada um. A unidade escolar precisava se enquadrar em um ou mais critérios e a classificação se daria pela pontuação.

De acordo com notícia veiculada, em 5 de junho de 2013, no Portal do Ministério da Educação (MEC), o PDDE-ES contava com um orçamento de R 100 milhões para que escolas localizadas em "municípios em estado de vulnerabilidade ambiental pudessem desenvolver iniciativas voltadas para a sustentabilidade", e essa informação foi ratificada pelo relato a seguir:

Na época nós procuramos entender em qual critério fomos contemplados e o técnico da Secretaria de Educação informou que as escolas se enquadraram no primeiro critério devido a poluição do rio que corta a nossa cidade, que era um aspecto muito forte aqui no município. (Coordenadora UE15)

De acordo com os entrevistados, antes da implantação do Programa ocorreu uma reunião com todos os gestores, dirigida pelo servidor responsável pelos programas educacionais do MEC. Nessa reunião, foram apresentados o PDDE-ES e o PDE Interativo (plataforma utilizada pelas escolas públicas como ferramenta de planejamento e gestão, bem como para realizar adesão aos programas do MEC):

Tivemos uma reunião com todos os gestores da rede, para apresentação do programa. (Coordenadora UE15)

Na verdade, o PDE Interativo é auto-explicativo, então a partir do momento que íamos acessando ele ia instruindo e sinalizando o próximo passo, dando opções para que a gente escolhesse o que ficaria melhor para nosso projeto. (Diretora da UE20) 
Nos relatos acima, observa-se que muitos educadores se dispõem a fazer o melhor, independente do suporte que lhes é dado. Todavia, a capacitação promove a reflexão sobre o conceito de sustentabilidade, possibilitando prever os desafios e auxilia na elaboração de estratégias para alcançá-la. A capacitação específica para questões ambientais ajuda aos educadores a introduzir perspectivas disciplinares, interdisciplinares e transdisciplinares sobre as questões ambientais em sua prática pedagógica, dando importante contribuição para efetivar os Objetivos de Desenvolvimento Sustentável (ODS).

De acordo com a Resolução n. ${ }^{\circ}$ 2/2012, em seu artigo 19:

Os órgãos normativos e executivos dos sistemas de ensino devem articular-se entre si e com as universidades e demais instituições formadoras de profissionais da educação, para que os cursos e programas de formação inicial e continuada de professores, gestores, coordenadores, especialistas e outros profissionais que atuam na Educação Básica e na Superior capacitem para o desenvolvimento didático-pedagógico da dimensão da Educação Ambiental na sua atuação escolar e acadêmica (MEC, 2012b).

Para a UNESCO, a capacitação dos educadores e diretores escolares "ajuda as escolas a incorporar a sustentabilidade em suas salas de aula, operações e gestão", assegurando "o desenvolvimento de práticas, princípios, programas e parcerias de sustentabilidade" (UNESCO, 2017, p. 50). Assim sendo, a capacitação é fundamental para uma boa aplicabilidade do Programa e dos recursos e, sabendo disso, os idealizadores do PNES incluíram como ação inicial a realização do processo formativo denominado "Escolas Sustentáveis e Com-Vida", que, segundo Wiziack (2013) foi realizado na modalidade à distância.

\subsection{Desafios e dificuldades enfrentados para transformar a escola num espaço educador sustentável}

Apesar de Wiziack et al (2013), Grohe (2015), Bastos e Rabonovick (2016) afirmarem que o processo formativo "Escolas Sustentáveis e Com-Vida" foi disponibilizado a escolas do Estado da Bahia, a presente pesquisa revelou que essa capacitação não chegou a todos os envolvidos e a falta de uma capacitação que promovesse uma análise mais aprofundada sobre o PNES foi citada pelos entrevistados como o principal desafio para a execução desse Programa no município:

A dificuldade que tivemos foi não conhecer profundamente o programa, mas ter que executá-lo e aplicar o recurso. Me senti insegura quando tive que investir o recurso e pedi ajuda à Secretaria. (Diretora UE26)

Como já foi dito, a formação continuada em educação ambiental é indispensável ao processo de ensino-aprendizagem, sendo apontada como uma necessidade dos educadores:

Eu acho que a formação continuada de toda a equipe escolar é uma forma de sairmos do senso comum, para um conhecimento mais elaborado, mais científico. E, é através da formação continuada que a educação ambiental terá um avanço. Pois, o que tenho observado é que as questões relacionadas a 
temática ambiental ainda estão muito no "basiquinho”. (Diretora UE5)

Dessa maneira, processos formativos em educação ambiental possibilitam aos educadores o domínio de conhecimentos e, consequentemente, mudanças conceituais e procedimentais. Essa mudança, por sua vez, possivelmente, promoverá aprendizagens e o desenvolvimento de habilidades, atitudes e comportamentos nos educandos além de valores que possibilitem entender e transformar a realidade socioambiental, tal como propõe o Programa Nacional de Educação Ambiental - ProNEA.

Outro desafio refere-se ao recurso financeiro liberado, visto que foram evidenciadas críticas quanto ao valor, ao parcelamento, ao tempo de liberação e à falta de continuidade do programa:

O principal problema foi a insuficiência dos recursos para a manutenção do programa, faltou recurso financeiro, material e humano para que o programa fosse contínu e permanente, pois para cuidar do meio ambiente precisamos de recursos (...). Então uma das falhas desse programa foi ter pensado em ações momentâneas, não se pensou na continuidade do programa e das ações que nasceram dele. É necessário que a escola recebesse pelo menos anualmente uma quantia para manutenção dessas ações que foram desenvolvidas durante a culminância desse projeto. (Coordenadora UE7)

O maior problema foi o recurso ser parcelado e descontínuo, pois foi dado apenas o primeiro passo, mas para a Educação Ambiental ser contínua e permanente, como preconizam as políticas públicas, é necessário que o recurso seja mantido com periodicidade. Pois a educação ambiental não se faz em um ano ou em dois, $o$ que a comunidade usufruiu de 2014 a 2016, a clientela atual não está usufruindo da mesma maneira, pois para darmos sequência ao programa se faz necessário a manutenção da verba também. (Coordenadora UE27)
As depoentes se referiram ao décimo artigo da Lei 9.795/99 que preconiza que "A educação ambiental será desenvolvida como uma prática educativa integrada, contínua e permanente em todos os níveis e modalidades do ensino formal" e apesar dos percalços encontrados durante a execução da proposta, foi unânime o apelo a continuidade do Programa Nacional Escola Sustentáveis e da disponibilização do auxílio financeiro pelo MEC/FNDE. No entanto, cabe ressaltar que, conforme manual, o PDDE-ES seria uma "forma de incentivar, com recursos financeiros, as escolas que já realizam ações voltadas à educação ambiental" (MEC, 2013, p. 6).

Logo, tanto a Resolução CD/FNDE n. ${ }^{\circ}$ 18/2013 quanto a Resolução CD/FNDE n. ${ }^{\circ}$ 18/2014 deixam claro que essa assistência financeira disponibilizada pelo PDDE-ES seria apenas um incentivo à escolas que já desenvolviam projetos de educação ambiental e, dando continuidade aos seus projetos, as escolas promoveriam ações voltadas à melhoria da qualidade de ensino apoiadas na adoção de critérios de sustentabilidade socioambiental, articulando o currículo, a gestão e o espaço físico, passando a se tornar espaços educadores sustentáveis.

\subsection{Contribuições do PDDE-ES para o espaço físico da escola, a gestão e no currículo}

A proposta Escolas Sustentáveis estabelece que os três eixos currículo, gestão e espaço físico devem estar inter-relacionados e ter intenção de educar.

Diante dessa concepção, considerando as recomendações do Manual Escolas Sustentáveis, do ano de 2013, e do Guia de Orientações Operacionais, de 
2014, que trata das orientações a respeito do PNES, foram analisados aspectos relevantes dos eixos gestão, espaço físico e currículo, bem como suas contribuições para que as escolas, alvo da pesquisa, fizessem a transição para uma escola sustentável do ponto de vista socioambiental.

Conforme esses documentos, para a dimensão Gestão, as ações passíveis de financiamento referem-se ao apoio à criação e ao fortalecimento da Comissão de Meio Ambiente e Qualidade de Vida na Escola (Com-Vida) e dentre os itens financiáveis desse eixo destaca-se a realização de oficinas voltadas à formação dos integrantes, aquisição de equipamentos e subsídios teórico-metodológicos e pedagógicos que motivassem a reflexão sobre as mudanças socioambientais globais, o planejamento de ações de transição para a sustentabilidade e a possibilidade de deslocamentos para conhecer iniciativas relacionadas à sustentabilidade socioambiental (MEC, 2013, p. 3).

Para o eixo Gestão, verificou-se que todas as escolas envolvidas na pesquisa contemplaram no Plano de Ação "apoiar a criação e fortalecimento da Comissão de Meio Ambiente e Qualidade de Vida na Escola (Com-Vida)". No entanto, constatou-se que, apesar de adquirirem os equipamentos e/ou materiais para tal ação, nenhum entrevistado soube falar sobre a criação e atuação da Com-Vida durante a execução dos recursos do PDDE-ES. Essa informação foi ratificada ao analisar os Projetos Políticos Pedagógicos (PPP) das escolas, não sendo encontrada nenhuma informação sobre a Com-Vida ou planejamento de ações que a contemplasse.

Vale destacar que, nas escolas pesquisadas, apenas em 2018, durante a realização da V Conferência Nacional Infantojuvenil pelo Meio Ambiente (V CNIJMA), é que duas escolas decidiram implan- tar a Com-Vida, conforme relato das coordenadoras pedagógicas:

Nós temos a Com-Vida, que fazem parte professores, alunos e pais, foi implantada em 2018 durante a V CNIJMA e ainda está em fase de estruturação e formulação da agenda. (Coordenadora UE9)

Implantamos este ano, durante a realização da Etapa Escolar da V CNIJMA. (Coordenadora UE15)

A Comissão de Meio Ambiente e Qualidade de Vida na Escola objetiva facilitar o planejamento participativo da Agenda 21 na escola, buscando também a inserção curricular da temática ambiental. A Com-Vida tem papel fundamental na transição das escolas rumo à sustentabilidade socioambiental, uma vez que permeia os eixos Gestão e Currículo e auxilia indiretamente na eficácia do eixo Espaço Físico, contribuindo também com a melhoria na qualidade de ensino, sendo, portanto, essencial a sua inserção no Projeto Político Pedagógico das escolas.

O Manual Escolas Sustentáveis recomenda para o eixo Currículo a inclusão da temática socioambiental no PPP da escola e dentre os itens financiáveis estão: realização de oficinas de formação e da produção e/ou aquisição de materiais didático-pedagógicos, campanhas educativas e outras ações consideradas relevantes pelo coletivo escolar (MEC, 2013, p. 4).

A fim de inserir a temática ambiental em seu currículo, 10\% das unidades escolares (UE) adquiriram materiais para divulgação da temática na comunidade e entorno, fazendo campanhas educativas.

Além disso, todas as unidades escolares avaliadas investiram parte do recurso recebido na aquisição de materiais didático-pedagógicos como 
jogos, livros e vídeos, com objetivo de se trabalhar a temática ambiental com os alunos:

Para o currículo, conseguimos adquirir alguns materiais pedagógicos, como livros paradidáticos, jogos e um material pedagógico para os professores trabalharem a temática ambiental. (Diretora UE3)

Vale destacar que alguns materiais adquiridos não fazem qualquer referência à temática ambiental como, por exemplo, jogos matemáticos, dorso humano, etc.

Ainda sobre o eixo currículo, o Manual prevê a "inclusão de conhecimentos, saberes e práticas sustentáveis no Projeto Político-Pedagógico" (MEC, 2013, p. 2). Ao ser questionado sobre a inserção da temática ambiental no Projeto Político-Pedagógico, $7,0 \%$ dos entrevistados, relataram que o PPP estava sendo atualizado e afirmaram que pretendiam contemplar a temática neste instrumento pedagógico.

Ao avaliar o PPP de cada escola contemplada com o PDDE-ES, a fim de verificar a atual situação referente à temática ambiental, constatou-se que $61,0 \%$ das escolas pesquisadas não contemplavam a temática ambiental, o que fere o artigo oitavo das DCNEA:

A Educação Ambiental, respeitando a autonomia da dinâmica escolar e acadêmica, deve ser desenvolvida como uma prática educativa integrada e interdisciplinar, contínua e permanente em todas as fases, etapas, níveis e modalidades, não devendo, como regra, ser implantada como disciplina ou componente curricular específico (MEC, 2012b).

Segundo os Parâmetros Curriculares Nacionais - PCN, os conteúdos de Meio Ambiente devem estar "integrados às áreas, numa relação de transversalidade, de modo que impregne toda a prática educativa e, ao mesmo tempo, crie uma visão global e abrangente da questão ambiental" (MEC, 1997, p. 193).

Vale destacar que esses dois documentos reforçam o desenvolvimento da visão global das questões ambientais nos alunos através da interdisciplinaridade. Todavia, o predomínio da visão fragmentada do conhecimento pelos professores foi usada como argumento preponderante para justificar a exclusão da educação ambiental da prática pedagógica:

A educação ambiental é um tema transversal e deve permear todas as disciplinas, não pode ser trabalhada em uma disciplina especifica, mas eu penso que isso deixa muito solto, pois nem todos os professores são compromissados com esta temática. Em resumo, eu vejo um paradoxo muito complexo, pois se fala muito da importância dessa temática, mas pouco se vê os educadores trazendo esse tema para seu planejamento de aula ou desenvolvendo projetos. (Diretora UE23)

(...) a educação ambiental é tão difícil de ser trabalhada nas escolas, porque estamos tão apegados ao conteúdo programático de cada disciplina e não se consegue inserir a educação ambiental no planejamento. (Coordenadora UE9)

Quanto a isso, Bonotto \& Carvalho (2016) advertem para a necessidade de repensar a prática pedagógica e de se criar espaços para discussão da temática ambiental, bem como a dimensão de valores:

Enquanto a escola estiver preocupada somente em cumprir uma proposta curricular a todo custo, com resultados de avaliações, e não der espaço às questões valorativas que fazem o aluno pensar, não avançaremos no processo educativo. A escola tem que aceitar esse desafio, disponibilizando tempo para trabalhar 
com essas questões, e tempo é algo que a sociedade está sempre a atropelar (Bonotto \& Carvalho, 2016, p. 57).

Continuando a analisar os PPP, verificou-se que a educação ambiental está presente em 39,0\% desses documentos, sendo contemplada na forma de projetos. Porém, em sua maioria, os projetos encontravam-se como anexo, aparentando ser um segmento que pode ser suprimido, a qualquer tempo, desse importante documento:

Por mais que saibamos da importância, por mais que a gente vivencie, por mais que esteja implícito em nosso dia a dia é muito difícil incorporar a temática no nosso planejamento semanal e vai ficando em projetos soltos e esses projetos isolados vão ficando em segundo plano, pois a demanda é tão grande e ai a gente vai priorizando outros projetos. (Diretora UE20)

A DCNEA estimula a inserção da educação ambiental nos projetos da escola e, a partir de uma reflexão crítica sobre a temática, propõe que sua integração ao currículo extrapole a simples distribuição do tema pelos demais componentes. Dessa maneira, a educação ambiental deve contemplar uma abordagem curricular integrada e transversal, contínua e permanente em todas as áreas de conhecimento, componentes curriculares e atividades escolares.

Conforme os PCN que versam sobre a temática Meio Ambiente, a abordagem curricular transversal representa a "transformação dos conceitos, a explicitação de valores e a inclusão de procedimentos, sempre vinculados à realidade cotidiana da sociedade, de modo que obtenha cidadãos mais participantes" (MEC, 1997, p. 193).
Para que a interdisciplinaridade seja alcançada, o PCN- Meio Ambiente orienta que a organização curricular seja um trabalho realizado em conjunto e que a construção de projetos pedagógicos parta do diálogo e da interação de todos os sujeitos que compõem a comunidade escolar, possibilitando a construção de atitudes e valores. Assim, os projetos voltados para trabalhar a temática ambiental de forma transversal se configuram como principal ferramenta na construção de "valores sociais, conhecimentos e habilidades, atitudes e competências voltadas para a conservação do meio ambiente, bem de uso comum do povo, essencial à sadia qualidade de vida e sua sustentabilidade. (Brasil, 1999, Artigo $1^{\circ}$ )

Apesar do número expressivo de escolas que incluíam a temática ambiental em seu PPP, verificou-se que a maneira como a temática ambiental vem sendo trabalhada não promove a internalização de "valores éticos, estéticos e morais em torno do cuidado com o ambiente" (Carvalho \& Toniol, 2012, p.2), sendo também desprovida de aprofundamento científico, desarticulada dos componentes curriculares, descontínua, resultando numa prática pedagógica ingênua e superficial, sendo a temática ambiental abordada com base em datas comemorativas como o Dia da Água, Dia da Árvore, Dia do Meio Ambiente, sinalizando que a educação ambiental está longe de "adotar uma abordagem que considere a interface entre a natureza, a sociocultura, a produção, o trabalho, o consumo", e que possa promover uma visão crítica e politizada, conforme preconiza a DCNEA, em seu sexto artigo (Brasil, 2012b).

De acordo com a Resolução CD/FNDE n. ${ }^{\circ}$ 18/2014, o PDDE - Escolas Sustentáveis tem por objetivo estimular processos pedagógicos voltados 
para o desenvolvimento da sustentabilidade socioambiental, possibilitando que as escolas contempladas com esse auxílio financeiro tornem-se espaços educadores sustentáveis. Vinculada a isto, deve-se considerar que, no momento que uma escola acolhe a temática ambiental como proposta, é necessário repensar o seu currículo e ajustá-lo aos objetivos e aos princípios da educação ambiental.

Com base nesse pressuposto, questionou-se sobre as contribuições do PNES para o currículo, apenas $15,0 \%$ dos entrevistados afirmaram ter contribuído, o que demonstra que uma contradição entre os objetivos do PNES e a prática pedagógica.

Contudo, observou-se que essa contribuição foi muito importante, não só durante a execução dos Planos de Ação exigidos para adesão ao PDDE-ES, mas continua contribuindo em seis escolas, fazendo compreender que mais importante que a quantidade, é a qualidade:

O currículo teve um grande avanço, pois os profissionais da área pedagógica perceberam a importância de se trabalhar a educação ambiental em todas as linguagens. Esse programa serviu de incentivo para trabalharmos a sustentabilidade, qualidade de vida, vida saudável. Houve um despertar dos profissionais e a preocupação em inserir a educação ambiental de forma transversal nas diferentes atividades executadas na escola. (Coordenadora UE27)

Outra ação financiável pelo PNES refere-se ao eixo Espaço Físico. Analisando os Planos de Ação, observou-se que este eixo foi o que mais teve adesão durante a execução do recurso financeiro disponibilizado via PDDE-ES. Todos os entrevistadosrelataram que houve significativas contribuições, como por exemplo:
Quando eu cheguei aqui em 2008, a escola tinha outra estrutura, depois houve uma reforma que deu um "up" na estética da escola, tornando o ambiente escolar muito mais agradável e arejado. Foi feito também o jardim que deixou a escola mais bonita e atraente. (Diretora UE25)

Nós tínhamos uma área externa enorme, porém feia e descuidada (...). Com a ajuda dos alunos fizemos um jardim lindo. (...) Também foi feita a horta ao lado desse jardim, onde os alunos plantam, cuidam e a produção é utilizada na merenda escolar. (...) E esses dois espaços são utilizados, pelos professores, para aula ao ar livre. (Diretora UE17)

Entre elas, está a horta, que tinha uma pessoa para cuidar e também a participação de alunos do $8^{\circ}$ e $9^{\circ}$ ano, que ajudavam a plantar, limpar, enfim a cuidar da horta. Era uma horta muito produtiva, inclusive dava de tudo nessa horta como melancia, alface e temperos que colaborava com a merenda escolar. Outra ação foi a construção do jardim onde era um barranco, quando chovia a lama descia. Então, foi feito o jardim que além de deixar a escola mais bonita e agradável, também auxiliou na limpeza da escola e no trabalho dos funcionários. (Diretora UE7)

O Manual estabelece que o recurso deva ser utilizado para "Adequar o espaço físico, visando à destinação apropriada de resíduos da escola, eficiência energética e uso racional da água, conforto térmico e acústico, mobilidade sustentável e estruturação de áreas verdes" (MEC, 2013a, p. 9). No entanto, foi detectada divergência entre o que está estabelecido nos documentos orientadores do PNES e a gestão do recurso:

No espaço físico foi feito a reforma: revestimento de piso e paredes, colocamos tomadas, arrumamos a parte hidráulica. (Diretora UE19) 
Quando eu assumi, a gestão dessa escola tinha em conta R \$ 10.400,00. Nós gastamos em torno de R \$ 9.000,00 com a reforma dos banheiros e estruturação da secretaria. (Diretora UE15)

Detalhando melhor tem-se o seguinte enredo: um grupo gestor fez o diagnóstico da realidade da escola, identificando os principais problemas a serem superados. Esse grupo, juntamente com a comunidade escolar, fez o planejamento buscando soluções para os problemas elencados e recebeu o recurso do PDDE-ES na conta do caixa escolar da UEx da escola. Porém não tiveram tempo hábil para executar o plano de ação, tendo então que reprogramar o recurso para o exercício seguinte. No entanto, com a mudança de gestão, muitos sucessores iniciaram a execução do recurso sem conhecer o PNES e a verba foi aplicada em outras necessidades da escola.

Mais uma vez, ressalta-se a importância da Com-Vida na gestão dos recursos, pois se as escolas tivessem suas respectivas Comissões, estruturadas e atuantes, não haveria tantos desencontros de informações, mesmos com a mudança dos gestores de cada escola.

O Guia de Orientações Operacionais do PNES (2014) estabelece que o recurso destina-se a tornar o local sustentável. No entanto, ao analisar as pastas de prestação de contas e confrontando as informações com os dados obtidos na observação do local, constatou-se que em muitas UE's o termo "adequar" foi compreendido como sinônimo de "reformar", sendo o recurso aplicado em situações necessárias

TABELA 2 - Levantamento das ações referentes à aplicação do recurso destinado ao eixo espaço físico, nas escolas contempladas com o PDDE-ES, em um município localizado na região Sudoeste da Bahia, Brasil.

\begin{tabular}{llc}
\hline \multicolumn{1}{c}{ AÇÕES } & \multicolumn{1}{c}{ ATIVIDADE } & $\begin{array}{c}\text { UNIDADES ESCO- } \\
\text { LARES (\%) }\end{array}$ \\
\hline Conforto térmico & Telhado com telha de cerâmica, ventiladores e janelas. & 14,6 \\
\hline Gestão eficiente da água & Torneira, caixa e bomba d'água. & 12,2 \\
\hline Gestão eficiente da energia & Lâmpadas, tomadas e fios. & 19,5 \\
\hline $\begin{array}{l}\text { Saneamento e destinação adequada } \\
\text { de resíduos }\end{array}$ & Lixeira de coleta seletiva e fossa séptica. & 31,7 \\
\hline Convivência da comunidade escolar & $\begin{array}{l}\text { Cobertura do pátio, refeitório, jardim com bancos e per- } \\
\text { golado. }\end{array}$ & 36,6 \\
\hline Segurança alimentar e nutricional & $\begin{array}{l}\text { Ativação e/ou criação de hortas, que promovem a aprendi- } \\
\text { zagem e auxiliam na merenda escolar. }\end{array}$ & 34,1 \\
\hline Mobilidade/acessibilidade & Construção de rampa de acesso. & 2,4 \\
\hline Ecossistemas locais & Ativação e/ou criação de jardins utilizando plantas nativas. & 19,5 \\
\hline Reforma* & $\begin{array}{l}\text { Pintura, confeção e instalação de portão, recuperação da } \\
\text { estrutura física da escola (reboco, janelas, portas, forro), } \\
\text { confecção e instalação de divisórias. }\end{array}$ & 53,7 \\
\hline
\end{tabular}

*Diverge dos itens financiáveis conforme Guia de Orientações Operacionais .

FONTE: Próprios autores. 
a cada escola, contudo, sem associação a questões referentes à sustentabilidade no ambiente escolar, conforme levantamento detalhado na Tabela 2 .

Não se pode negar que as recuperações da estrutura física das escolas influenciam no bem estar e na segurança da comunidade escolar, a exemplo de pintura das portas e paredes, confecção e instalação do portão. Contudo, concluí-se que o termo "reforma" diverge daquilo que é proposto no Programa Nacional Escolas Sustentáveis visto que as atividades identificadas na ação "Reforma" da Tabela 2 em nada promovem a sustentabilidade socioambiental dos/nos sujeitos que compõem aquela unidade escolar e distanciam-se dos objetivos do programa.

Conforme os documentos orientadores do PNES, o programa se tornará uma experiência exitosa a partir da articulação dos três eixos (currículo, espaço físico e gestão), haja vista que o currículo valoriza saberes científicos e estimula "a responsabilidade e o engajamento individual e coletivo na transformação local e global", a gestão, por sua vez, encoraja o diálogo, a democracia e a participação e o espaço físico proporciona "melhores condições de aprendizagem e de convívio social” (Brasil, 2012a, p. 11-12).

\subsection{Mudanças de valores, atitudes e comportamentos}

No bojo dos objetivos para alcançar uma educação ambiental de qualidade, a DCNEA estabelece no artigo 14, inciso V, “o estímulo à constituição de instituições de ensino como espaços educadores sustentáveis, integrando proposta curricular, gestão democrática, edificações, tornando-as referências de sustentabilidade socioambiental" (MEC, 2012b).

O espaço educador sustentável ou a escola sustentável deve ter a intenção de educar para a sustentabilidade socioambiental de suas comunidades, tornando-se referência para seu território e disseminando a cultura da sustentabilidade. Isto posto, quando questionado se o PNES contribuiu com a disseminação da cultura da sustentabilidade na escola e entorno, constatou-se que $35,0 \%$ dos entrevistados consideraram que não houve contribuição:

Houve a manutenção e adequação do espaço físico, aquisição de material permanente, mas a cultura da sustentabilidade não foi trabalhada. (Diretora UE31-41)

Na verdade não houve, não se trabalhou o projeto, focou apenas na aplicação do recurso. (Diretora UE26)

Todavia, 65,0\% dos participantes não compartilharam dessa opinião, como pode ser visto nos relatos a seguir:

Acredito que Oficina de Sabão foi o divisor de águas do PNES aqui na escola. Porque saiu dos muros da escola e disseminou a consciência ambiental, falamos com as mães sobre os prejuizos ao jogar o óleo na pia, ensinamos a reutilização desse material que gerou uma economia financeira $e$ até uma fonte de renda, pois algumas mães já fazem e vendem o sabão para aumentar a renda familiar. Isso, para mim, é sustentabilidade. (Diretora UE17)

Contribuiu bastante, as adequações feitas no espaço possibilitaram maior integração da comunidade escolar, despertando o cuidado com nosso patrimônio e trabalhamos com a conscientização 
com os alunos em relação ao meio ambiente de uma forma prática e leve, a partir do dia a dia dele aqui na escola. (Diretora UE16)

Foi uma grande contribuição, lembro que a diretora na época apresentou o programa para toda a comunidade e convidou a participar do programa. E hoje, não só os alunos, mas a comunidade também está envolvida com o cuidado com o meio ambiente. (Diretora UE21)

Na definição de que escola sustentável é aquela que "se torna referência de vida sustentável para sua comunidade", ou seja, a escola deve, enquanto espaço educador sustentável, ultrapassar os muros da escola e esta instituição transforma-se num modelo a ser seguido pela comunidade onde está situada. A escola deve deixar de ser ilha, isolada e fechada, passando a ser um centro de referência multiplicador de informações e experiências na comunidade, no bairro, no município em que está inserida, promovendo a reflexão sobre os impactos ambientais gerados por esses grupos sociais e também buscando maneiras de compensar os danos existentes e evitar prejuízos futuros.

\subsection{Avaliação da atuação da escola junto ao PDDE-ES}

Para finalizar, foi pedido aos entrevistados que avaliassem a atuação da escola junto à aplicação do recurso. Contabilizando o resultado, verificou-se que $37,0 \%$ dos entrevistados consideraram que a atuação foi suficiente, afirmando que foram atendidos os objetivos do Programa:

Todas as ações propostas e que constam em ata, foram executadas. Achei que o recurso foi bem empregado. (Diretora UE11).

Julgo positivo, nós aplicamos os recursos de acordo com as necessidades da escola. (Diretora UE15) Já os demais, correspondendo a 63,0\%, declararam que a atuação foi insuficiente:

Eu acho que poderia ter sido melhor aproveitado (...) Ocorre um desperdício de água muito grande, então poderia ter trocado as torneiras e até lavanderias que estão quebradas, poderia ter feito um sistema de reaproveitamento das águas de enxágue para lavar pátio. Acontecem, em média, 105 banhos por dia (...). Poderia ter adquirido um temporizador para os chuveiros. (...) poderia rever a parte elétrica, pois nós temos interruptores que ligam, simultaneamente, as lâmpadas de duas salas que são totalmente independentes, na área externa as lâmpadas são incandescentes ainda. Então veio $R \$ 8.000,00$ e a escola continua carente de muita coisa, que o PNES poderia ter ajudado a melhorar. (Diretora UE10)

Achei que ficou a desejar, pois utilizou-se os recursos na reforma da escola. Mas não se trabalhou a questão da sustentabilidade. (Diretora UE26)

Confrontando os dados obtidos por meio dos três instrumentos de pesquisa com os objetivos do Programa e os itens financiáveis, constatou-se que houve gestão inadequada do auxílio financeiro disponibilizado através do PDDE-ES em 12,0\% das escolas. Sendo que em:

- $\quad 4,8 \%$ houve negligência por não utilizarem os insumos adquiridos para realização da horta, chegando à perda de validade dos mesmos;

- $\quad 2,4 \%$ das escolas, apesar da aquisição de lâmpadas fluorescente (conforme pastas de prestação de contas), no pátio externo 
verificou-se o uso de lâmpadas incandescentes e conforme relato da diretora essas lâmpadas ficam acesas durante toda a noite, finais de semana e feriados, indicando ineficiência dos recursos energéticos;

- $4,8 \%$ das escolas utilizaram o recurso para realização de serviços contábeis, o que não está expressamente proibido, mas tal procedimento não se enquadra como uma ação socioambiental e, tampouco se encontra no rol de itens financiáveis indicado no Guia de Orientações Operacionais.

Lamentavelmente, comprovou-se que a sustentabilidade ambiental não é vista como prioridade em muitas escolas e precisa ser discutida no ambiente escolar:

A verba possibilitou adquirir determinadas coisas que só com Programa Educação Básica ou com a ajuda da Secretaria de Educação, nós não conseguiríamos. Então, foi priorizado outras necessidades da escola e o valor da verba foi aplicado nessas necessidades e, infelizmente, a educação ambiental não foi trabalhada da forma que deveria. (Diretora UE2)

Vale ressaltar que a utilização do recurso, conforme objetivos e princípios do PNES, permitiria iniciar uma transformação da escola em um espaço educador sustentável possibilitando uma relação equilibrada com o meio ambiente e garantindo a qualidade de vida às presentes e futuras gerações. Dessa maneira, a proposta Escolas Sustentáveis seria a materialização dos documentos legais e acordos, que postulam a educação ambiental como mola propulsora para um desenvolvimento mais sustentável. Pois na Escola Sustentável os estudantes se identificam como integrantes da natureza, o que facilita a assimilação de conhecimentos científicos, ao passo que exercem a cidadania.

Dessa maneira, o PNES significa muito mais que executar uma Política Pública para educação ambiental, e as escolas que aderiram ao PDDE-ES deveriam assumir um compromisso com a Educação para Sustentabilidade e, para tanto, deveriam trabalhar na ambientalização não só do espaço físico, mas do ensino como todo, visto que isso envolve a adaptação do espaço físico, do currículo e da gestão alinhados aos objetivos e princípios da educação ambiental.

\section{Considerações finais}

No atual contexto, a educação deve estar atenta para questões como: degradação ambiental, riscos e desastres naturais, pobreza e desigualdade social e, principalmente ameaças à paz e à segurança.

Diante disso, apoiado nos eixos Gestão, Currículo e Espaço Físico, o Programa Nacional Escolas Sustentáveis buscou oportunizar, por meio da criação de espaços educadores sustentáveis, o surgimento de agentes de mudança para a sustentabilidade.

No município estudado, comprovou-se que houve muitas tentativas de efetivação do Programa Nacional Escolas Sustentáveis. Porém, a ausência de preparo da equipe gestora revelou que muito além do desejo de transformar escolas em espaços educadores sustentáveis, é necessário um conhecimento teórico-metodológico aprofundado do PNES (conceitos, objetivos e princípios), bem como da educação ambiental como um todo.

A falta de conhecimento, de habilidade e/ou de empatia no que se refere à temática ambiental levou 
muitos gestores, sujeitos desta pesquisa, a visualizar o Programa Dinheiro Direto na Escola - Escolas Sustentáveis apenas como uma verba para atender às necessidades da "sua" unidade escolar, ignorando quase que totalmente os objetivos e princípios da ação agregada a qual o recurso estava atrelado.

A ausência de capacitação específica fez com que a gestão subjugasse a importância da Com-Vida que, por sua vez, promoveria na escola espaços de diálogos e de tomada de decisões, incentivando a comunidade escolar (incluindo estudantes e seus familiares) na construção de um roteiro para a transformação da escola em espaço educador sustentável.

Além disso, detectou-se uma falta de articulação entre os aspectos Gestão, Currículo e Espaço Físico, como se não houvesse relação entre esses elementos estruturais da escola. No entanto, a proposta Escolas Sustentáveis estimula a coerência entre o currículo, a gestão e o espaço físico, para a consolidação da sustentabilidade socioambiental no ambiente escolar.

A educação para a sustentabilidade apresenta-se como principal instrumento para se alcançar os Objetivos de Desenvolvimento Sustentável, visto que possibilita a toda comunidade escolar uma reflexão aprofundada sobre o conceito de desenvolvimento sustentável, ao passo que ponderam sobre suas próprias ações, enfatizando os impactos e a qualidade de vida das pessoas. Dessa maneira, o grande diferencial da educação para a sustentabilidade é o empoderamento dos educandos para agir de forma sustentável frente ao complexo cenário vivido atualmente, oportunizando aos indivíduos se tornarem agentes de mudança em suas sociedades, movendo-as rumo à sustentabilidade e, nesse contexto, a escola como espaço educador é essencial.
Uma escola na qual o currículo, a gestão e o espaço físico atuem em conjunto nas questões socioambientais pode ser considerada um espaço educador sustentável, sendo referência para a comunidade do seu entorno, para seu bairro, sua cidade, quiçá para a unidade federativa, levando a sustentabilidade socioambiental do local para o global.

Com a investigação dos documentos do PNES, de periódicos e, principalmente, a análise dos dados coletados nas escolas, foi possível concluir que o Programa Nacional Escolas Sustentáveis se configurou como a materialização das políticas públicas para educação ambiental no Brasil. Contudo, para transformar as escolas em espaços educadores sustentáveis, consolidando de forma "permanente e contínua as práticas pedagógicas das escolas de educação básica", faz-se necessário, entre outras coisas, investir em capacitação de qualidade para docentes e gestores, além do replanejamento quanto à liberação de auxílios financeiros.

Por conseguinte, faz-se necessário um maior (e melhor) suporte da Secretaria de Educação para essas escolas, suporte esse que não se restrinja apenas à aplicação de recursos, mas que tenha como cerne a ampliação do conhecimento do gerir a "coisa pública", adotando procedimentos de planejamento e gestão e, sobretudo, estabelecendo um diálogo verdadeiro com a escola, a fim de que os programas de educação ambiental promovam um conhecimento crítico, transformador e libertador.

\section{Referências}

Alves-Mazzotti, A. J.; Gewandsznajder, F. O método nas ciências naturais e sociais: pesquisa quantitativa e qualitativa. São Paulo: Pioneira, 2. ed., 2002. 
André, M. O que é um estudo de caso qualitativo em educação? Educação e Contemporaneidade, 22, 95-103, 2013. Disponível em: <https://www.revistas.uneb.br/index.php/ faeeba/article/view/753>

Bastos, B. D.; Rabonovici, A. A importância do processo de formação de educadores ambientais na efetividade do Programa Nacional Escolas Sustentáveis - PNES. Revista Brasileira de Educação Ambiental, 11, 42-59, 2016. Disponível em: www.sbecotur.org.br/revbea/index.php/revbea/ article/download/ 4966/3180.

Bonotto, D. M. B.; Carvalho, M. B. S. S. (Orgs.). Educação Ambiental e valores na escola: buscando espaços, investindo em novos tempos. São Paulo: Cultura Acadêmica, 2016.

Brasil. Lei 9.795, de 27 de abril de 1999. Institui a Política Nacional de Educação Ambiental. Brasília: DOU de 28/4/1999.

Carvalho, I. C. M.; Toniol, R. F. Ambientalização, cultura e educação: diálogos, traduções e inteligibilidades possíveis desde um estudo antropológico da educação ambiental. In: Berbel, N. A. N.; Pullin, E. N. M. (Org.). Pesquisas em educação: inquietações e desafios. Londrina: Editora da UEL, p. 523-538, 2012.

Duarte, R. Entrevistas em pesquisas qualitativas. Educar, 24, 213-225, 2004. Disponível em: <http:/www.scielo.br/ pdf/er/n24/n24a11.pdf>

Ferreira, C. A. L. Pesquisa quantitativa e qualitativa: perspectivas para o campo da educação. Revista Mosaico, 8, 173-182, 2015. Disponível em: <http://seer.pucgoias.edu. br/index.php/mosaico/article/download/4424/2546>

FNDE - Fundo Nacional de Desenvolvimento da Educação. Resolução CD/FNDE n. ${ }^{\circ} 18$, de 21 de maio de 2013. Destina recursos financeiros, a escolas públicas municipais,estaduais e distritais que possuam alunos matriculados na educação básica, a fim defavorecer a melhoria da qualidade de ensino e a promoção da sustentabilidadesocioambiental nas unidades escolares. Brasília: CD/FNDE,2013. Disponível em: $<$ https://www.fnde.gov.br/acesso-a-informacao/institucional/ legislacao?start=280>. Acesso em: mai. 2017.

FNDE - Fundo Nacional de Desenvolvimento da Educação. Resolução CD/FNDE n. ${ }^{\circ} 18$, de 3 de setembro de 2014. Dispõe sobre a destinação de recursos financeiros, nos moldes operacionais e regulamentares do Programa Dinheiro Direto na Escola (PDDE), a escolas públicas da educação básica, a fim de favorecer a melhoria da qualidade deensino e a promoção da sustentabilidade socioambiental nas unidades escolares. Brasília: CD/FNDE, 2014. Disponível em https: $</$ www.fnde.gov.br/acesso-a-informacao/institucional/ legislacao?start=280>. Acesso em: mai. 2017.

Fonseca, J. J. S. Metodologia da pesquisa cientifica. Fortaleza: UEC, 2002. Apostila. Disponível em: <http://www. ufrgs.br/cursopgdr/downloadsSerie/derad005.pdf $>$ Acesso em: set. 2019 .

Grohe, S. L. S. Escolas Sustentáveis: três experiências no município de São Leopoldo- RS. Rio Grande do Sul, Dissertação (Mestrado em Educação) - PUC-RS, 2015.

Günther, H. Pesquisa qualitativa versus pesquisa quantitativa: esta é a questão?. Psicologia: Teoria e Pesquisa, 22, 201-209, 2006. Disponível em<http://www.scielo.br/ $\mathrm{pdf} / \% 0 \mathrm{D} / \mathrm{ptp} / \mathrm{v} 22 \mathrm{n} 2 / \mathrm{a} 10 \mathrm{v} 22 \mathrm{n} 2 . \mathrm{pdf}>$

MEC. Ministério da Educação. Secretaria de Educação Fundamental. Parâmetros Curriculares Nacionais $\left(1^{a} \grave{a} 4^{a}\right.$ séries). Brasília: 1997.

MEC - Ministério da Educação, Secretaria de Educação Continuada, alfabetização,Diversidade e Inclusão, Ministério do Meio Ambiente. Vamos cuidar do Brasil comescolas sustentáveis: educando-nos para pensar e agir em tempos de mudançassocioambientais globais. Brasília: 2012. Disponível em:<http://www.seduc.go.gov.br/documentos/ nucleomeioambiente/material2013/caderno.pdf $>$. Acesso em: mai. 2017.

MEC - Ministério da Educação. Resolução n. ${ }^{\circ}$ 2, de 15 de junho de 2012. Estabelece asDiretrizes Curriculares Nacionais para a Educação Ambiental. Brasília: 2012.Disponível em: <http://conferenciainfanto.mec.gov.br/images/ conteudo/ivcnijma/diretrizes.pdf > . Acesso em: mai. 2017.

MEC - Ministério da Educação. Manual Escolas Sustentáveis, 2013. Disponível em: $<\mathrm{http}: / /$ pdeinterativo.mec.gov. br/escolasustentavel/manuais/Manual_Escolas Sustentaveis_v\%2005.07.2013.pdf>. Acesso em: mar. 2017.

MEC - Ministério da Educação. Programa Dinheiro Direto na Escola - PDDE EscolasSustentáveis: Guia de orientações operacionais. 2014. Disponível em: $<$ http://pdeinterati- 
vo.mec.gov.br/arquivo/pdf/Guia_PDDE_2014_Sustentavel. pdf>.Acesso em: mai. 2017.

MMA - Ministério do Meio Ambiente. Plano Nacional de Mudança do Clima. 2008. Disponível em:<http://www. mma.gov.br/estruturas/smcq_climaticas/_arquivos/plano_nacional_mudaca_clima.pdf $>$. Acesso em: ago. 2017.

ONU. Organização das Nações Unidas. Transformando Nosso Mundo: a Agenda 2030 para o Desenvolvimento Sustentável. ONU, 2015. Traduzido pelo Centro de Informação das Nações Unidas para o Brasil (UNIC Rio). Disponível em: <http://www.agenda2030.org.br/saiba_mais/publicacoes $>$. Acesso em: ago. 2018.

Silva, T. T. Documentos de Identidade: uma introdução às teorias do currículo. Belo Horizonte: Autêntica, 2005.

Souza, C. Políticas públicas: uma revisão da literatura. Sociologias, 16, 20-45, 2006. Disponível em:<http://www. scielo.br/pdf/soc/n16/a03n16>
Trajber, R.; Sato, M. Escolas Sustentáveis: Incubadoras de Transformações nas Comunidades. Revista Eletrônica do Mestrado em Educação Ambiental, v. especial, 70-78, 2010. Disponível em: <https://periodicos.furg.br/remea/ article/view/3396>

UNESCO. Organização das Nações Unidas para a Educação, a Ciência e a Cultura. Educação para os Objetivos de Desenvolvimento Sustentável: objetivos de aprendizagem. UNESCO, 2017. Disponível em: <http://unesdoc.unesco. org/images/0025/002521/252197por.pdf $>$. Acesso em: ago. 2018.

Wiziack, S. R. C.; Vargas, I. A.; Zanon, A. M.; Programa Escolas Sustentáveis: reflexões para uma formação de educadores ambientais no Brasil. In: Anais VII EPEA - Encontro Pesquisa em Educação Ambiental. Rio Claro - SP.07 a 10 de Julho de 2013. Disponível em:<http://www.epea.tmp. br/epea2013_anais/pdfs/plenary/0136-1.pdf $>$. Acesso em: out. 2018. 